\title{
A comparative bioefficacy of seed and root extracts of a medicinal plant, Withania somnifera when administered to prepupae of lepidopteran insects, Spodoptera litura (Lepidoptera: Noctuidae) and Pericallia ricini (Lepidoptera: Arctiidae)
}

\author{
Sandeep Kumar Gaur ${ }^{*}$ and Krishna Kumar
}

\begin{abstract}
Background: The lepidopterans, Spodoptera litura and Pericallia ricini, are polyphagous pests of agricultural importance. The unscrupulous and non-judicious use of chemical pesticides for controlling the insect pests has resulted into severe environmental hazards, threatening non-target organisms and human health.

Results: Administration of seed and root extracts of a medicinal plant, Ashwagandha (Withania somnifera) to prepupae of two economically important insect pests viz. S. litura and P. ricini resulted into disruption of molting and metamorphosis leading to a number of developmental aberrations such as prolongation of the life span of prepupae, postponement of pupal-adult ecdysis, ecdysial failure, reduced pupation and adult emergence, formation of larval-pupal and pupal-adult intermediates, abnormal pupae, and adultoids.

Treatment with seed extracts of $W$. somnifera was more effective as it alone caused mortality in both the lepidopteran insects viz. S. litura and P. ricini, whereas no such effect was observed when treated with root extracts. $P$. ricini was more susceptible to $W$. somnifera as it resulted into formation of larval-pupal-adult chimeras in addition to effects described earlier, whereas this effect was not observed in the case of S. litura.
\end{abstract}

Conclusion: These results are similar to these produced by the administration of JHAs and hence mimic their action by the way of interfering with the neuroendocrine system.

Keywords: Ashwagandha, Tobacco caterpillar, Hairy caterpillar, Ecdysial stasis, Larval-pupal intermediates, Pupaladult intermediates, Larval-pupal-adult chimeras, Abnormal pupae, Adultoids

\section{Background}

The unscrupulous and non-judicious use of chemical pesticides to control agricultural pests has resulted into severe adverse effects on the environment (Damalas \& Eleftherohorinos, 2011) because of its persistent and non-biodegradable nature (Gill \& Garg, 2014). These chemical pesticides are posing severe hazards to our environment and human health having serious biomagnifications such as contamination of food, soil, and water,

\footnotetext{
* Correspondence: gaurs808@gmail.com

Department of Zoology, University of Allahabad, Prayagraj 211002, India
}

adversely affecting biodiversity and wildlife (Ibrahim, 2016), causing toxicity to non-target organisms such as fish amphibian, fish-eating birds (gulls, terns, herons) (Gill \& Garg, 2014), fresh water organisms (Wan, 2013), pollinators, wild bees (Brittain, Vighi, Bommarco, Settele, \& Potts, 2010), insect-eating birds (partridges, grouse, pheasants), grain- and plant-feeding birds (Zacharia, 2011), and reptiles (Mingo, Lotters, \& Wagner, 2016). Human exposure is of great magnitude through ground application of pesticides in agricultural and public use to control insects (Badawy, 1998) which culminate in a 
negative impact on human health (Khan \& Damalas, 2015) such as immunotoxicity, endocrine disruption, antigenicity (Mokarizadeh, Faryabi, Rezvanfar, \& Abdollahi, 2015), carcinogenicity, endometriosis, birth defects, asthma (Chaturvedi, Sharma, \& Chaturvedi, 2013), neurological, psychological, and behavioral dysfunctions, hormonal imbalances, leading to infertility, breast pain, immune system dysfunction, reproductive system defects, genotoxicity, and blood disorders (Maksymiv, 2015). Insecticides of plant origin have a great potential and have been used as an alternative to synthetic chemical insecticides for pest management (Isman, 2006) because these are eco-friendly with target specificity, easily biodegradable, economically feasible (Pant, Dubey, \& Patanjali, 2016), ease of application (Rajapakse, Ratnasekera, \& Abeysinghe, 2016), and posing little threat to human health (El-Wakeil, 2013). Therefore, these plant derivatives can be used as an excellent insect growth regulators (IGRs).

Pericallia ricini Fabricius, 1775, also known as hairy caterpillar, is widely found in India and Sri Lanka (Witt et al., 2005) and is a major pest of castor, gingelly, cotton, country bean, banana, sunflower (David \& Ananthakrishnan, 2004), maize, and brinjal (Singh \& Gandhi, 2012). Hairy caterpillars defoliate the tender leaves and the growing shoot tips of Vanilla main cultivated field (Vanitha, Karuppuchamy, \& Sivasubramanian, 2011).

Spodoptera litura Fab., also known as tobacco caterpillar, is a polyphagous pest widely distributed all over India, Afghanistan, Burma, China, Japan, and Sri Lanka (Divya, 2016). It is a serious pest of more than 100 host plants including cultivated crops, vegetables, weeds, fruits, and ornamental plants (Ahmad, Ghaffar, \& Rafiq, 2013). The larvae of this pest are voracious feeders destroying leaves of the groundnut plant at flowering and seedling stages causing significant loss in the yield (Dhir, Mohapatra, \& Senapati, 1992). This pest has been found to exhibit widespread resistance to various insecticides (Abbas, Shad, \& Razaq, 2012; Ahmad, Arif, \& Ahmad, 2007; Ahmad, Sayyed, Saleem, \& Ahmad, 2008; Kranthi et al., 2002; Tong, Su, Zhou, \& Bai, 2013).

Withania somnifera (Family: Solanaceae), also known as Ashwagandha or Indian ginseng, is an important medicinal plant used extensively in Ayurveda, the classical Indian system of the medicine (Bhattacharya, Bhattacharya, Sairam, \& Ghosal, 2000). This medicinal plant possesses a spectrum of diverse phytochemicals such as alkaloids (withanine, withasomnine, somniferine), steroidal lactones (withaferins, withanolides), and steroids (stigmasterol, sitoinosides) that are responsible for a broad range of biological implications (Dar, Hamid, \& Ahmad, 2015). It is used as remedy for several disease due to its potential therapeutic effects such anti-inflammatory, antioxidant, anti-aging, anticancer, anti-anxiety, anti-depressant, anti-ulcer, antihypertensive, antimicrobial, cardioprotectant, immunomodulator, and hypoglycemic agent (Alam et al., 2012). Whereas the medicinal properties of Ashwagandha are well documented, its insect growth regulatory effects have not been described in details except in a few instances involving only last instar larvae of certain lepidopteran pests (Gaur \& Kumar, 2017a, 2017b). In the present communication, a comparative efficacy of seed and root extracts of Ashwagandha, W. somnifera, has been described as a result of administration of these to prepupae of two economically important lepidopteran pests viz. $S$. litura and P. ricini.

\section{Materials and methods Insect rearing}

Wild eggs of S. litura and P. ricini were collected from castor plant (Ricinus communis) in the Department of Zoology, University of Allahabad, Allahabad $\left(25^{\circ} 27^{\prime} \mathrm{N}\right.$ $\left.81^{\circ} 44^{\prime} \mathrm{E}\right)$, UP, India and kept in the BOD incubator at $26 \pm 2{ }^{\circ} \mathrm{C}, 70 \pm 5 \%$ relative humidity. After post hatching, neonate larvae were kept in sterilized glass troughs and provided soft, fresh, sterilized castor leaves for feeding. In order to maintain sanitation, the developing larvae were transferred daily to clean sterilized glass troughs and supplied with fresh sterilized leaves for feeding. When developing larvae reached the penultimate larval instar, they were transferred to glass troughs containing $3-5$ " of sterilized sawdust. The last instar larvae of $S$. litura pupated in the sawdust, whereas the last instar larvae of $P$. ricini pupated by forming cocoons attached to the walls of the glass troughs. The pupal duration lasted for 7-9 days in case of S. litura and 9-11 days in $P$. ricini, and thereafter, adult moths emerged. The adult moths were kept in ventilated cages $(30 \times 30 \times 30 \mathrm{~cm})$ and given $10 \%$ honey solution for feeding and fresh castor leaves for oviposition.

\section{Plant material and extraction}

The dried seeds of $W$. somnifera were purchased online from Srivilliputtur, Tamil Nadu (India). The seeds were washed thoroughly with distilled water and dried at room temperature away from sunlight for a week and grinded with the help of grinder to obtain a fine powder, whereas the dried root powder of $W$. somnifera was purchased online from Srijain Ayurvedic Pharmacy, Kattedan, Hyderabad (India).

The acetone extract of seed and root of W. somnifera was prepared according to the method of Gaur and Kumar (2017a, 2017b). $125 \mathrm{~g}$ of seed and root powder were separately weighed and dissolved in $500 \mathrm{ml}$ of acetone and heated at $50{ }^{\circ} \mathrm{C}$ for 2 days using Soxhlet apparatus and filtered through Whatman no. 1 filter paper. In 
order to ensure complete evaporation of acetone from the filterates, the filerates were condensed by using rotatory evaporator under reduced pressure of $22-26 \mathrm{mmHg}$ at $45^{\circ} \mathrm{C}$ resulting into formation of a dark brown, sticky, thick paste of crude extract of seeds and roots of $W$. somnifera. The desired doses were obtained by dissolving $1 \mathrm{mg}$ of crude extract into $1 \mathrm{ml}$ pure acetone and kept at $4{ }^{\circ} \mathrm{C}$.

\section{Experimental procedure}

Twenty prepupae each of $S$. litura and $P$. ricini were administered topically with $5 \mu \mathrm{g}, 10 \mu \mathrm{g}, 15 \mu \mathrm{g}$, and $20 \mu \mathrm{g}$ doses of seed and root extracts of $W$. somnifera on the dorsum of the posterior abdomen with the help of a microapplicator according to method of Singh and Kumar (2015a). Controls were treated with similar doses of pure acetone only. After treatment, both the treated and control prepupae were transferred to sterilized glass troughs containing saw dust for pupation. All the experiments were replicated thrice. Observations were recorded $3 \mathrm{~h}$ post treatment till the emergence of adultoids/adults. All the dead and malformed/deformed specimens were fixed in Bouin's fluid and preserved in $70 \%$ ethyl alcohol for morphological studies and photography.

\section{Statistical analysis}

All the data regarding duration of prepupae and pupal-adult ecdysis were subjected to one-way ANOVA to find out significant difference between mean prepupal and pupal-adult duration of the treated and control groups. Correlation coefficient was also calculated to determine the correlation between the doses administered and various morphological deformities observed. All the calculations were done using Graph Pad Prism 2007, 5.01 software (San Diego, California).

\section{Results}

Topical administration of seed and root extracts of $W$. somnifera to prepupae of $S$. litura and P. ricini resulted into disruption of growth, molting, and metamorphosis. The developmental abnormalities as a consequence of treatment of both the seed and root extracts of W. somnifera in S. litura and P. ricini comprised delay in prepupal and pupal-adult ecdysis, ecdysial stasis, formation of larval-pupal and pupal-adult intermediates, reduction in pupation and adult emergence, and formation of abnormal pupae and adultoids.

\section{Mortality}

Administration of seed extracts of $W$. somnifera to prepupae of S. litura and P. ricini resulted into mortality in a dose-dependent manner showing a positive correlation both in S. litura $(r=0.90)$ (Table 1$)$ and P. ricini $(r=$ 0.98 ) (Table 3). However, no mortality occurred when prepupae of $S$. litura and $P$. ricini were treated with root extracts of W. somnifera (Tables 2 and 4 ).

\section{Prepupal duration}

The prepupal duration was prolonged significantly in a dose-dependent manner as a consequence of treatment of prepupae of both the insects viz. S. litura and P. ricini with the seed and root extracts of $W$. somnifera (Tables 1 , 2,3 , and 4).

In $S$. litura, there was a maximum prolongation of mean prepupal duration up to 0.84 days $(F=14.31$; $\mathrm{df}=$ 4 , 245; $p \leq 0.001)(r=0.87)$ (Table 1$)$ at a dose of $20 \mu \mathrm{g}$ with seed treatment, whereas it was 0.32 days $(F=3.65$; $\mathrm{df}=4,268 ; p \leq 0.01)(r=0.82)$ at the same dose with root treatment as compared to control (Table 2). Conversely, in $P$. ricini, the mean prepupal duration was prolonged up to 0.54 days $(F=8.41 ; \mathrm{df}=4,257 ; p \leq 0.001)(r=0.96)$ at $20 \mu \mathrm{g}$ dose with root treatment (Table 4 ), whereas it was only up to 0.29 days $(F=4.18 ; \mathrm{df}=4,235 ; p \leq 0.01)$ $(r=0.86)$ at the same dose with seed treatment as compared to controls (Table 3 ).

Therefore, treatment with seed extracts was more effective in inducing prolongation of prepupal duration in $S$. litura as compared to similar result induced by treatment with root extracts in P. ricini.

Table 1 Topical administration of seed extracts of Withania somnifera on prepupal stage of Spodoptera litura $(n=20$; replicate =3)

\begin{tabular}{|c|c|c|c|c|c|c|c|c|c|c|c|}
\hline $\begin{array}{l}\text { Dose } \\
(\mu \mathrm{g})\end{array}$ & $\begin{array}{l}\text { Prepupal } \\
\text { duration } \\
\text { (Mean } \pm \text { SE) }\end{array}$ & $\begin{array}{l}\text { Pupal-adult } \\
\text { ecdysis } \\
\text { (Mean } \pm \text { SE) }\end{array}$ & $\begin{array}{l}\text { Mortality } \\
\text { (\%) }\end{array}$ & $\begin{array}{l}\text { Ecdysial } \\
\text { failure } \\
(\%)\end{array}$ & $\begin{array}{l}\text { Larval-pupal } \\
\text { intermediates } \\
(\%)\end{array}$ & $\begin{array}{l}\text { Pupation } \\
\text { (\%) }\end{array}$ & $\begin{array}{l}\text { Abnormal } \\
\text { pupae (\%) }\end{array}$ & $\begin{array}{l}\text { Pupal-adult } \\
\text { intermediates } \\
(\%)\end{array}$ & $\begin{array}{l}\text { Adult } \\
\text { emergence } \\
(\%)\end{array}$ & $\begin{array}{l}\text { Normal } \\
\text { adults } \\
(\%)\end{array}$ & $\begin{array}{l}\text { Adultoids } \\
\text { (\%) }\end{array}$ \\
\hline 0 & $0.56 \pm 0.04$ & $7.52 \pm 0.07$ & 0 & 0 & 0 & 100 & 0 & 0 & 100 & 100 & 0 \\
\hline 5 & $1.15 \pm 0.09^{a}$ & $8.23 \pm 0.30^{b}$ & 2 & 43 & 8 & 47 & 2 & 8 & 37 & 20 & 17 \\
\hline 10 & $1.24 \pm 0.11^{a}$ & $8.33 \pm 0.40^{b}$ & 5 & 48 & 15 & 32 & 2 & 5 & 25 & 10 & 15 \\
\hline 15 & $1.31 \pm 0.10^{a}$ & $8.31 \pm 0.35^{b}$ & 8 & 52 & 8 & 32 & 2 & 8 & 22 & 12 & 10 \\
\hline \multirow[t]{2}{*}{20} & $1.40 \pm 0.11^{a}$ & $8.40 \pm 0.37^{b}$ & 23 & 41 & 13 & 23 & 2 & 5 & 16 & 5 & 11 \\
\hline & $(r=+0.87)$ & $(r=+0.80)$ & $\begin{array}{l}(r=+ \\
0.90)\end{array}$ & $\begin{array}{l}(r=+ \\
0.68)\end{array}$ & $(r=+0.71)$ & $\begin{array}{l}(r= \\
-0.86)\end{array}$ & $(r=+0.71)$ & $(r=+0.48)$ & $(r=-0.84)$ & $\begin{array}{l}(r=- \\
0.79)\end{array}$ & $\begin{array}{l}(r=+ \\
0.36)\end{array}$ \\
\hline
\end{tabular}


Table 2 Topical administration of root extracts of Withania somnifera on prepupal stage of Spodoptera litura $(n=20$; replicate =3)

\begin{tabular}{|c|c|c|c|c|c|c|c|c|c|c|}
\hline $\begin{array}{l}\text { Dose } \\
(\mu \mathrm{g})\end{array}$ & $\begin{array}{l}\text { Prepupal } \\
\text { duration (Mean } \\
\pm \text { SE) }\end{array}$ & $\begin{array}{l}\text { Pupal-adult } \\
\text { ecdysis (Mean } \pm \\
\text { SE) }\end{array}$ & $\begin{array}{l}\text { Ecdysial } \\
\text { failure } \\
(\%)\end{array}$ & $\begin{array}{l}\text { Larval-pupal } \\
\text { intermediates } \\
(\%)\end{array}$ & $\begin{array}{l}\text { Pupation } \\
\text { (\%) }\end{array}$ & $\begin{array}{l}\text { Abnormal } \\
\text { pupae (\%) }\end{array}$ & $\begin{array}{l}\text { Pupal-adult } \\
\text { intermediates } \\
\text { (\%) }\end{array}$ & $\begin{array}{l}\text { Adult } \\
\text { emergence } \\
(\%)\end{array}$ & $\begin{array}{l}\text { Normal } \\
\text { adults } \\
(\%)\end{array}$ & $\begin{array}{l}\text { Adultoids } \\
\text { (\%) }\end{array}$ \\
\hline 0 & $0.52 \pm 0.04$ & $7.45 \pm 0.06$ & 0 & 0 & 100 & 0 & 0 & 100 & 100 & 0 \\
\hline 5 & $0.78 \pm 0.08^{c}$ & $7.74 \pm 0.07^{c}$ & 25 & 10 & 65 & 2 & 5 & 58 & 38 & 20 \\
\hline 10 & $0.80 \pm 0.09^{c}$ & $7.77 \pm 0.09^{c}$ & 33 & 10 & 57 & 0 & 5 & 52 & 32 & 20 \\
\hline 15 & $0.82 \pm 0.08^{c}$ & $7.80 \pm 0.10^{b}$ & 27 & 15 & 58 & 2 & 6 & 50 & 35 & 15 \\
\hline \multirow[t]{2}{*}{20} & $0.84 \pm 0.06^{b}$ & $7.88 \pm 0.08^{\mathrm{a}}$ & 28 & 10 & 62 & 2 & 5 & 55 & 42 & 13 \\
\hline & $(r=+0.82)$ & $(r=+0.89)$ & $\begin{array}{l}(r=+ \\
0.71)\end{array}$ & $(r=+0.72)$ & $\begin{array}{l}(r= \\
-0.73)\end{array}$ & $(r=+0.58)$ & $(r=+0.73)$ & $(r=-0.74)$ & $\begin{array}{l}(r=- \\
0.66)\end{array}$ & $\begin{array}{l}(r=+ \\
0.40)\end{array}$ \\
\hline
\end{tabular}

Significant at 0.001

${ }^{\mathrm{b}}$ Significant at 0.01

'Significant at 0.05 ; one-way ANOVA; $r=$ correlation coefficient

\section{Pupal-adult ecdysis}

Administration of seed and root extracts of W. somnifera to prepupae of S. litura and P. ricini resulted into significantly increased pupal-adult ecdysis duration as compared to controls, showing a positive correlation between the doses administered and prolongation of pupal-adult ecdysis at all the doses of seed and root extracts of W. somnifera (Tables 1, 2, 3, and 4).

There was a maximum prolongation of 0.88 days $(F=$ $4.73 ; \quad \mathrm{df}=4, \quad 115 ; p \leq 0.05) \quad(r=0.80) \quad($ Table 1$) \quad$ in pupal-adult ecdysis at $20 \mu \mathrm{g}$ when S. litura prepupae were treated with $W$. somnifera seed extracts as compared to only 0.43 days $(F=5.40 ; \mathrm{df}=4,184 ; p \leq 0.001)$ $(r=0.89)$ (Table 2) at the same dose when treated with root extracts.

Similarly, the pupal-adult ecdysis was increased to a maximum of 1.36 days $(F=9.93 ; \mathrm{df}=4,145 ; p \leq 0.001)$ $(r=0.89)$ (Table 3$)$ at $20 \mu \mathrm{g}$ when prepupae of $P$. ricini were treated with seed extracts of $W$. somnifera as compared to only 1.08 days $(F=8.22 ; \mathrm{df}=4,163 ; p \leq 0.001)$ $(r=0.86)$ (Table 4) in case of root treatment at the same dose.

Therefore, seed extracts of W. somnifera were much more effective in causing postponement of pupal-adult ecdysis in both $S$. litura and $P$. ricini as compared to root extracts of $W$. somnifera.

\section{Ecdysial failure}

Ecdysial failure was observed as a result of treatment of prepupae of both S. litura and P. ricini with seed and root extracts of $W$. somnifera (Tables 1, 2, 3, and 4).

Depending upon the degree of abnormality, the ecdysial stasis caused by the seed and root extracts of $W$. somnifera in polyphagous pest, S. litura could be broadly classified into the following types:

1. Pupa with larval exuviae attached to whole ventral surface of abdomen, dorsal surface of posterior abdomen including posterior extremity of the body
(Plate 1b). In some cases, larval exuviae remained attached to entire ventral surface of the pupa, whereas it was found adhered to only posterior region of the dorsal abdomen (Plate 1c) or larval exuviae attached to ventral surface of the abdomen of pupae (Plate 1d)

2. Pupa deformed and twisted having larval exuviae attached to ventral surface of head, thorax, and abdomen and posterior region of dorsal abdomen (Plate 1e).

3. Pupa with larval head capsule remained attached to ventral surface of head region; deformed thoracic legs and proboscis; reduced pupal cremaster (Plate 1f).

Depending upon the extent of abnormality, the ecdysial failure caused by the seed and root extracts of $W$. somnifera in hairy caterpillar, P. ricini could be divided into the following types:

1. Prepupa showing complete ecdysial failure, unable to cast off larval exuviae (Plate 2b).

2. Pupa with larval exuviae attached to all over the body surface except at the dorsal surface of thorax (Plate 2c).

3. Pupa with white and untanned antennae; larval exuviae found attached to the ventral and dorsal surfaces of the abdomen (Plate $2 \mathrm{~d}$ ).

4. Abnormal white untanned pupa with larval exuviae attached to entire ventral surface and dorsal region of posterior abdomen (Plate 2e).

5. Abnormal pupa showing deformity in the adjoining area between thorax and abdomen and larval exuviae attached to ventral surface of the body and dorsal surface of posterior abdomen (Plate 2f). In some pupae, the anterior part of the body including head and thorax was extremely malformed and twisted with larval exuviae attached to entire ventral surface of the body (Plate $2 \mathrm{~g}$ ). 


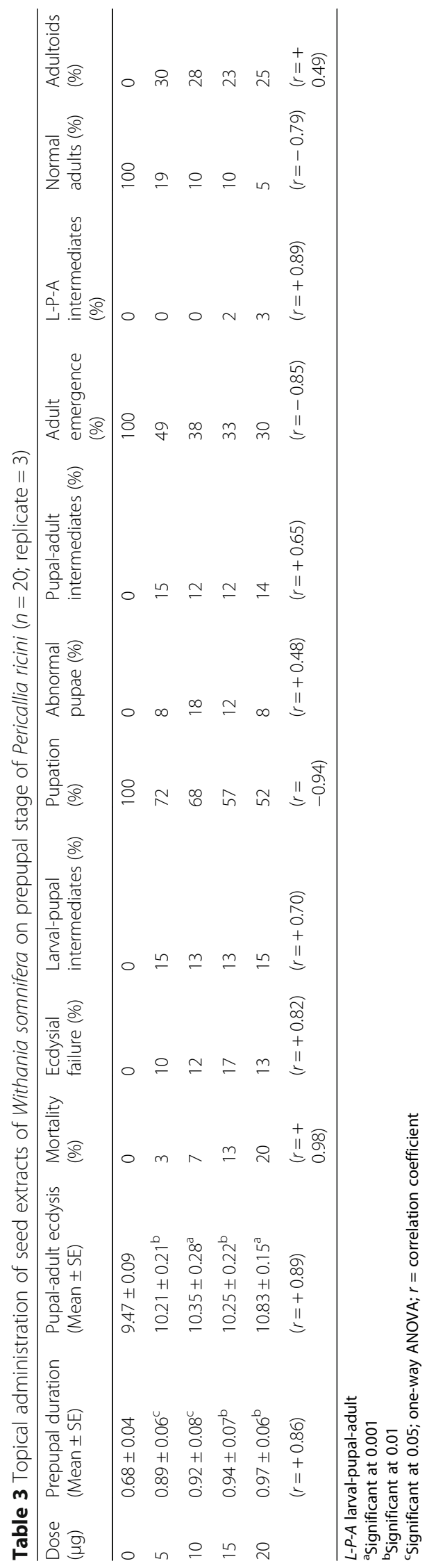


Table 4 Topical administration of root extracts of Withania somnifera on prepupal stage of Pericallia ricini $(n=20$; replicate =3)

\begin{tabular}{|c|c|c|c|c|c|c|c|c|c|c|c|}
\hline $\begin{array}{l}\text { Dose } \\
(\mu \mathrm{g})\end{array}$ & $\begin{array}{l}\text { Prepupal } \\
\text { duration } \\
\text { (Mean } \pm \\
\text { SE) }\end{array}$ & $\begin{array}{l}\text { Pupal- } \\
\text { adult } \\
\text { ecdysis } \\
\text { (Mean } \pm \\
\text { SE) }\end{array}$ & $\begin{array}{l}\text { Ecdysial } \\
\text { failure } \\
(\%)\end{array}$ & $\begin{array}{l}\text { Larval-pupal } \\
\text { intermediates } \\
(\%)\end{array}$ & $\begin{array}{l}\text { Pupation } \\
\text { (\%) }\end{array}$ & $\begin{array}{l}\text { Abnormal } \\
\text { pupae (\%) }\end{array}$ & $\begin{array}{l}\text { Pupal-adult } \\
\text { intermediates } \\
(\%)\end{array}$ & $\begin{array}{l}\text { Adult } \\
\text { emergence } \\
(\%)\end{array}$ & $\begin{array}{l}\text { L-P-A } \\
\text { intermediates } \\
(\%)\end{array}$ & $\begin{array}{l}\text { Normal } \\
\text { adults } \\
(\%)\end{array}$ & $\begin{array}{l}\text { Adultoids } \\
\text { (\%) }\end{array}$ \\
\hline 0 & $0.64 \pm 0.04$ & $9.40 \pm 0.08$ & 0 & 0 & 100 & 0 & 0 & 100 & 0 & 100 & 0 \\
\hline 5 & $\begin{array}{l}0.88 \pm \\
0.07^{c}\end{array}$ & $\begin{array}{l}10.19 \pm \\
0.21^{\mathrm{b}}\end{array}$ & 13 & 15 & 72 & 7 & 12 & 53 & 0 & 23 & 30 \\
\hline 10 & $\begin{array}{l}0.96 \pm \\
0.07^{\mathrm{b}}\end{array}$ & $\begin{array}{l}10.23 \pm \\
0.23^{\mathrm{b}}\end{array}$ & 23 & 10 & 67 & 13 & 17 & 37 & 2 & 7 & 30 \\
\hline 15 & $\begin{array}{l}0.99 \pm \\
0.07^{b}\end{array}$ & $\begin{array}{l}10.33 \pm \\
0.20^{\mathrm{a}}\end{array}$ & 24 & 23 & 53 & 8 & 4 & 41 & 2 & 8 & 33 \\
\hline \multirow[t]{2}{*}{20} & $\begin{array}{l}1.18 \pm \\
0.09^{\mathrm{a}}\end{array}$ & $\begin{array}{l}10.48 \pm \\
0.26^{\mathrm{a}}\end{array}$ & 30 & 15 & 55 & 2 & 8 & 45 & 2 & 7 & 38 \\
\hline & $(r=+0.96)$ & $(r=+0.86)$ & $\begin{array}{l}(r=+ \\
0.95)\end{array}$ & $(r=+0.71)$ & $\begin{array}{l}(r=- \\
0.91)\end{array}$ & $(r=+0.15)$ & $(r=+0.19)$ & $(r=-0.75)$ & $(r=+0.87)$ & $\begin{array}{l}(r=- \\
0.79)\end{array}$ & $\begin{array}{l}(r=+ \\
0.82)\end{array}$ \\
\hline
\end{tabular}

L-P-A larval-pupal-adult

a Significant at 0.001

${ }^{\mathrm{b}}$ Significant at 0.01

'Significant at 0.05 ; one-way ANOVA; $r$ = correlation coefficient

\section{Larval-pupal intermediates}

Topical administration of seed and root extracts of $W$. somnifera to prepupal instar of S. litura and P. ricini resulted into formation of larval-pupal intermediates in all the treated groups (Tables 1, 2, 3, and 4).

The larval-pupal intermediates produced by the administration of seed and root extracts of W. somnifera to S. litura could be broadly classified into following types:

1. Larval-pupal intermediate having shrunken body; anterior half (head and thorax) larval in appearance whereas abdomen showing pupal characteristics; larval exuviae remained attached to all over body surface (Plate $1 \mathrm{~g}$ ).

2. Larval-pupal intermediate consisting of larval head and thorax, whereas abdomen pupal in appearance; rudimentary larval prolegs present on the abdomen; larval exuviae still attached to dorsal surface and posterior extremity of the body (Plate $1 \mathrm{~h}$ ).

3. Larval-pupal intermediate with anterior half larval and posterior half pupal in appearance with pupal cremaster (Plate 1i).

4. Larval-pupal intermediate with larval head and thorax having two pairs of larval thoracic legs whereas metathoracic legs, wings, and abdomen showing pupal characteristics (Plate 1j).

The larval-pupal intermediates produced by the treatment of seed and root extracts of W. somnifera to $P$. ricini could be classified into following types:

1. Larval-pupal intermediate with wholly pupal body but with white, untanned larval prolegs and anal proleg; pupal body also showing abnormalities such as reduced left wing as compared to right wing; white and untanned left prothoracic and mesothoracic legs and distal part of proboscis; anterior part of the abdomen and conspicuous intersegmental spaces in the abdomen remained white and untanned (Plate $2 \mathrm{~h}$ ). In some cases, intermediates with pupal body having larval prolegs and larval exuviae attached to posterior extremity of the body were also found (Plate 2i) or intermediates with larva/anal prolegs and swollen, bulged, untanned right wing (Plate $2 \mathrm{j}$ )

2. Intermediate with pupal body showing reduced left fore wing, whereas hind wing was white and untanned; larval prolegs present on the abdomen and the larval exuviae attached to all along the ventral surface of the body (Plate $2 \mathrm{k}$ ).

3. Larval-pupal intermediate consisting of larval head and thorax, whereas abdomen pupal in appearance bearing larval prolegs; larval exuviae attached all over the dorsal surface of the body and posterior extremity of the abdomen (Plate $2 \mathrm{l}$ ).

4. Larval-pupal intermediate consisting of anterior half of the body larval and posterior half pupal in appearance; larval exuviae attached to dorsal surface of middle abdomen; abdomen partially tanned (Plate $2 \mathrm{~m}$ ).

5. Larval-pupal intermediate consisting of pupal body but with larval head; thorax with all its appendages remained highly deformed and untanned; anal prolegs present and larval exuviae attached to entire ventrolateral surface of the body (Plate $2 \mathrm{n}$ ).

6. Larval-pupal intermediate consisting of pupal body showing highly reduced fore wings, left hind wing; membranous and untanned right hind wing and 


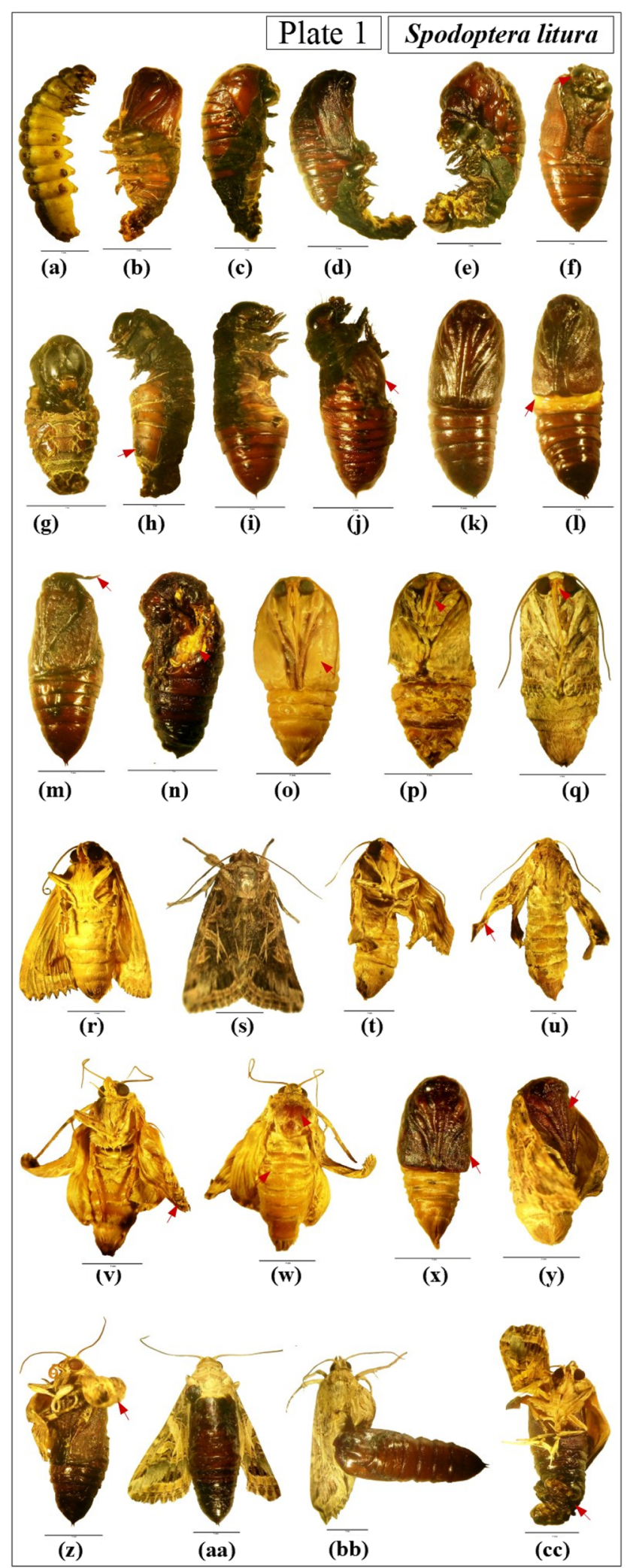

Plate 1 (See legend on next page.) 
(See figure on previous page.)

Plate 1 a Latero-ventral view of normal prepupa of S. litura. $\mathbf{b}$ Ventral view of pupa with larval exuviae attached to whole ventral surface of abdomen, $5 \mu \mathrm{g}$ seed extracts of $W$. somnifera. $\mathbf{c}$ Lateral view of pupa with larval exuviae remained attached to posterior ventral surface of abdomen, $10 \mu \mathrm{g}$ root extracts of $W$. somnifera. $\mathbf{d}$ Lateral view of pupa with larval exuviae attached to ventral surface of abdomen, $15 \mu \mathrm{g}$ root extracts of $W$. somnifera. e Lateral view of deformed pupa having larval exuviae attached to ventral head, thorax, and abdomen, $10 \mu \mathrm{g}$ seed extracts of $W$. somnifera. $\mathbf{f}$ Ventral view of pupa with larval head capsule, $20 \mu \mathrm{g}$ root extracts of $W$. somnifera. $\mathbf{g}$ Ventral view of larval-pupal intermediate having shrunken body, $10 \mu \mathrm{g}$ seed extracts of $\mathbf{W}$. somnifera. $\mathbf{h}$ Lateral view of larval-pupal intermediate with rudimentary larval prolegs, $15 \mu \mathrm{g}$ root extracts of $W$. somnifera. $\mathbf{i}$ Lateral view of larval-pupal intermediate with anterior half larval and posterior half pupal in appearance, $20 \mu \mathrm{g}$ seed extracts of $\mathbf{W}$. somnifera. $\mathbf{j}$ Lateral view of larval-pupal intermediate with pupal wings, $15 \mu \mathrm{g}$ root extracts of $\mathbf{W}$. somnifera. $\mathbf{k}$ Ventral view of normal pupa. I Ventral view of abnormal pupa with reduced wings, $10 \mu \mathrm{g}$ seed extracts of $W$. somnifera. $\mathbf{m}$ Ventral view of abnormal pupa with free right antenna, $10 \mu \mathrm{g}$ root extracts of $W$. somnifera. $\mathbf{n}$ Lateral view of abnormal pupa with white and untanned right hind wing, $20 \mu \mathrm{g}$ seed extracts of $W$. somnifera. o Ventral view of pupal-adult intermediate with white and untanned pupal proboscis, labial palpi, and wings, $15 \mu \mathrm{g}$ root extracts of $W$. somnifera. $\mathbf{p}$ Ventral view of pupal-adult intermediate with highly reduced pupal proboscis, $10 \mu \mathrm{g}$ seed extracts of $W$. somnifera. q Ventral view of pupal-adult intermediate with extremely reduced right proboscis, $5 \mu \mathrm{g}$ seed extracts of $W$. somnifera. $\mathbf{r}, \mathbf{s}$ Ventral and dorsal view of normal adult. $\mathbf{t}$, $\mathbf{u}$ Ventral and dorsal view of adultoid with crumpled wings, $20 \mu \mathrm{g}$ root extracts of $W$. somnifera. $\mathbf{v}, \mathbf{w}$ Ventral and dorsal view of adultoid with less scales on crumpled wings, $10 \mu \mathrm{g}$ seed extracts of $W$. somnifera. $\mathbf{x}$ Ventral view of adultoid with pupal exuviae, $5 \mu \mathrm{g}$ root extracts of $W$. somnifera. $\mathbf{y}$ Ventral view of adultoid with pupal exuviae attached to ventral surface of head and thorax, $15 \mu \mathrm{g}$ seed extracts of $W$. somnifera. $\mathbf{z}$ Ventral view of adultoid with deformed body unable to eclose from pupal exuviae, $20 \mu \mathrm{g}$ root extracts of $W$. somnifera. aa Dorsal view of adultoid with pupal exuviae remained attached to abdomen, $5 \mathrm{\mu g}$ seed extracts of $W$. somnifera. bb Dorsal view of adultoid with pupal cuticle not shed off and attached to right wing, $10 \mu \mathrm{g}$ root extracts of $W$. somnifera. cc Ventral view of adultoid with larval exuviae remained attached to pupal cuticle, $20 \mu \mathrm{g}$ seed extracts of $W$. somnifera. Bar $=5 \mathrm{~mm}$; red arrow shows deformities

metathoracic legs; antennae, pro, and mesothoracic legs partially tanned; rudiments of larval prolegs found on the abdomen (Plate 2o). In some cases, right antenna was reduced and directed toward the dorsal surface of the body (Plate 2p).

7. Larval-pupal intermediate with pupal body showing reduced and deformed proboscis whereas thoracic legs partially larval in appearance and presence of abdominal and anal prolegs (Plate $2 \mathrm{q}$ )

\section{Pupation}

Administration of seed extracts of $W$. somnifera to prepupae of $P$. ricini resulted into reduction in percentage pupation. The percentage pupation was reduced from $100 \%$ in controls to $72 \%, 68 \%, 57 \%$, and $52 \%$ at $5 \mu \mathrm{g}$, $10 \mu \mathrm{g}, 15 \mu \mathrm{g}$, and $20 \mu \mathrm{g}$ doses respectively showing negative correlation between the doses administered and the percentage pupation in a dose dependent manner $(r=-$ 0.94) (Table 3).

The percentage pupation was also reduced with treatment of seed and root extracts of $W$. somnifera to prepupae of $S$. litura and root extracts of $W$. somnifera treatment to $P$. ricini. There was a negative correlation between the doses administrated and the percentage pupation (Tables 1, 2, 3, and 4).

\section{Abnormal pupae}

Administration of seed and root extracts of $W$. somnifera to prepupae of S. litura resulted into formation of abnormal pupae. Abnormal pupae consisted of reduced wings and ventral surface of anterior abdomen white and unsclerotized (Plate $1 \mathrm{l}$ ). In some pupae, the right antenna was free and not glued to the body (Plate $1 \mathrm{~m}$ ) or highly deformed pupa with extremely reduced fore wing, white, unsclerotized right hind wing, and free proboscis not glued to the body (Plate $1 \mathrm{n}$ ).

Administration of seed and root extracts of W. somnifera to prepupae of $P$. ricini also resulted into formation of abnormal pupae.

Depending upon the degree of abnormalities, these have been classified into following types:

1. Abnormal pupa with partially tanned, swollen, bulged left wing; both the wings reduced; white antennae; left prothoracic leg, right mesothoracic leg, and anterior part of ventral abdomen untanned; intersegmental spaces between abdominal sclerites unusual in being unsclerotized and extended (Plate $2 \mathrm{~s}$ ).

2. Abnormal pupa showing partially white, untanned right mesothoracic leg, distal end of metathoracic legs, and anterior part of ventral abdomen (Plate 2 t)

3. Abnormal pupa with reduced, swollen bulged left fore wing (Plate $2 \mathrm{u}$ ).

4. Abnormal pupa with highly deformed body parts like eyes, proboscis, crumpled and reduced wings; undeveloped thoracic legs; white, untanned, and deformed abdomen (Plate $2 \mathrm{v}$ ).

5. Abnormal pupa with reduced, less tanned left wing; white and untanned proximal and distal part of right antenna (Plate $2 \mathrm{w}$ ).

\section{Pupal-adult intermediates}

Topical administration of seed and root extracts of $W$. somnifera to prepupae of S. litura resulted into formation of pupal-adult intermediates. 


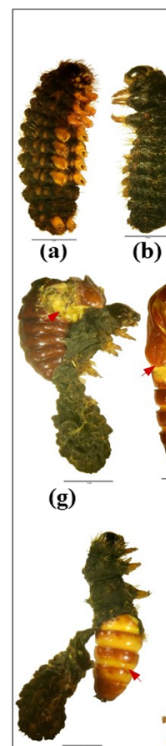

(m)

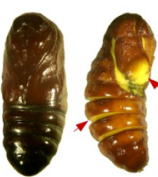

(r)

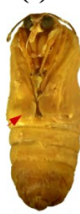

(x)

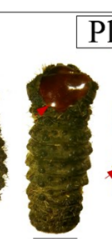

(c)

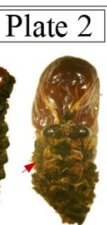

(d)

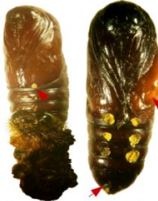

(h) (e)

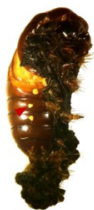

(k)

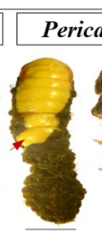

(I)

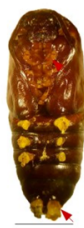

(n)

(o)

(p)

(q)

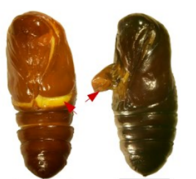

(u)

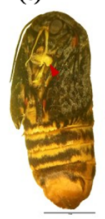

(z)

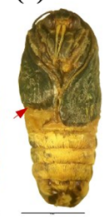

(aa)

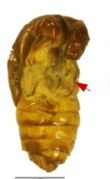

(v)

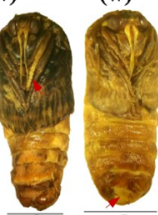

(bb)

(cc)

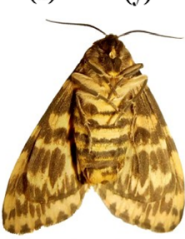

(dd)

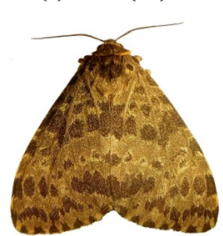

(ee)

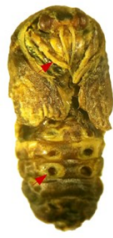

(ff)

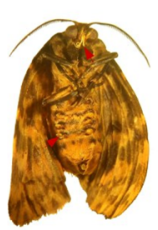

(gg)

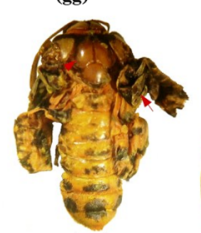

(jj)

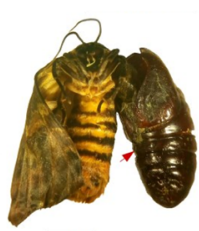

(hh)

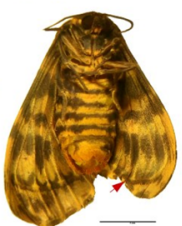

(kk)

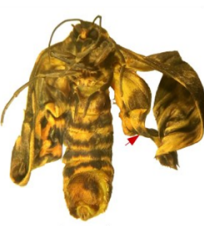

(ii)

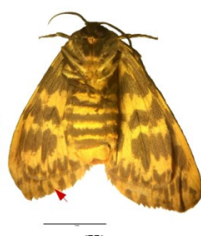

(Il)

Plate $\mathbf{2}$ a Latero-ventral view of normal prepupa of $P$. ricini. $\mathbf{b}$ Lateral view of prepupa showing complete ecdysial failure, $15 \mu \mathrm{g}$ seed extracts of $W$. somnifera. c Dorsal view of pupa with larval exuviae ruptured only from dorsal surface of thorax, $5 \mu \mathrm{g}$ root extracts of $W$. somnifera. $\mathbf{d}$ Ventral view of pupa with larval exuviae attached to whole ventral surface of abdomen, $10 \mu \mathrm{g}$ seed extracts of $W$. somnifera. e Dorsal view of white untanned pupa with larval exuviae, $20 \mu \mathrm{g}$ seed extracts of $W$. somnifera. $\mathbf{f}$ Lateral view of abnormal pupa with larval exuviae attached to entire ventral surface of abdomen, $15 \mu \mathrm{g}$ root extracts of $W$. somnifera. $\mathbf{g}$ Lateral view of abnormal pupa with malformed thorax and larval exuviae attached to whole ventral surface of the body, $20 \mu \mathrm{g}$ seed extracts of $W$. somnifera. $\mathbf{h}$ Ventral view of larval-pupal intermediate with larval prolegs and reduced left wing, $5 \mu \mathrm{g}$ seed extracts of $W$. somnifera. $\mathbf{i}$ Ventral view of larval-pupal intermediate with larval prolegs and larval exuviae, $10 \mu \mathrm{g}$ seed extracts of $W$. somnifera. $\mathbf{j}$ Ventral view of larval-pupal intermediate with swollen right wing and larval prolegs, $15 \mu \mathrm{g}$ seed extracts of $W$. somnifera. $\mathbf{k}$ Ventro-lateral view of larvalpupal intermediate with reduced left fore wing, $20 \mu \mathrm{g}$ seed extracts of $W$. somnifera. I Lateral view of larval-pupal intermediate with larval thoracic legs and larval prolegs, $5 \mu \mathrm{g}$ root extracts of $W$. somnifera. m Lateral view of larval-pupal intermediate with partially tanned pupal abdomen, $10 \mu \mathrm{g}$ root extracts of $W$. somnifera. $\mathbf{n}$ Ventral view of larval-pupal intermediate with highly deformed and untanned thoracic region, $15 \mu \mathrm{g}$ root extracts of $W$. somnifera. o Ventral view of larval-pupal intermediate with rudimentary larval prolegs, $20 \mu \mathrm{g}$ root extracts of $W$. somnifera. $\mathbf{p}$ Ventral view of larval-pupal intermediate with reduced right antenna, $15 \mu \mathrm{g}$ seed extracts of $W$. somnifera. q Ventral view of larval-pupal intermediate with partial larval thoracic legs, larval prolegs and anal prolegs, $20 \mu \mathrm{g}$ seed extracts of $W$. somnifera. $\mathbf{r}$ Ventral view of normal pupa. $\mathbf{s}$ Lateral view of abnormal pupa with intersegmental spaces between abdominal sclerites, $10 \mu \mathrm{g}$ root extracts of $W$. somnifera. $\mathbf{t}$ Ventral view of abnormal pupa with white, untanned anterior part of ventral abdomen, $15 \mu \mathrm{g}$ seed extracts of $W$. somnifera. $\mathbf{u}$ Ventral view of abnormal pupa with swollen left fore wing, $5 \mu \mathrm{g}$ seed extracts of $W$. somnifera. $\mathbf{v}$ Ventral view of abnormal pupa with undeveloped thoracic legs, $15 \mu \mathrm{g}$ root extracts of $W$. somnifera. $\mathbf{w}$ Ventral view of abnormal pupa with less tanned left wing, $5 \mu \mathrm{g}$ root extracts of $W$. somnifera. $\mathbf{x}$ Ventral view of pupal-adult intermediate with pupal abdomen, $20 \mu \mathrm{g}$ seed extracts of $W$. somnifera. $\mathbf{y}$ Ventral view of pupal-adult intermediate with white, bifurcated pupal proboscis, $15 \mu \mathrm{g}$ root extracts of $W$. somnifera. $\mathbf{z}$ Ventral view of pupal-adult intermediate with reduced right metathoracic leg, $15 \mu \mathrm{g}$ seed extracts of $W$. somnifera. aa Ventral view of pupal-adult intermediate with reduced left wing, $5 \mu \mathrm{g}$ root extracts of $W$. somnifera. bb Ventral view of pupal-adult intermediate with untanned right prothoracic leg, $20 \mu \mathrm{g}$ seed extracts of $W$. somnifera. cc Ventral view of pupal-adult intermediate with undeveloped genitalia, $10 \mu \mathrm{g}$ root extracts of $W$. somnifera. dd, ee Ventral and dorsal view of normal adult. ff Ventral view of larval-pupal-adult intermediate, $20 \mu \mathrm{g}$ root extracts of $W$. somnifera. gg Ventral view of larval-pupal-adult intermediate with larval prolegs and pupal proboscis, $10 \mu \mathrm{g}$ seed extracts of $W$. somnifera. hh Ventral view of adultoid with pupal exuviae, $5 \mu \mathrm{g}$ root extracts of $W$. somnifera. ii Ventral view of adultoid with crumpled wings, $15 \mu \mathrm{g}$ seed extracts of $W$. somnifera. jj Dorsal view of adultoid devoid of scales in the head and thorax region and deformed wings, $10 \mu \mathrm{g}$ seed extracts of $W$. somnifera. $\mathbf{k k}$ Ventral view of adultoid with reduced right wing, $5 \mu \mathrm{g}$ root extracts of $W$. somnifera. II Ventral view of adultoid with reduced left wing, $20 \mu \mathrm{g}$ seed extracts of $W$. somnifera. Bar $=5 \mathrm{~mm}$; red arrow pointing out the deformities 
Depending upon the degree of pupal and adult characters, pupal-adult intermediates have been classified into following types:

1. Pupal-adult intermediate consisted of white, untanned, bifurcated proboscis, labial palpi, wings pupal in appearance, whereas pigmented eyes, partially tanned antennae and legs and a few scales present on anterior and middle abdomen comprised adult characteristics; genitalia covered with scales (Plate 10)

2. Pupal-adult intermediate consisted of white, untanned, bifurcated, and highly reduced proboscis; highly reduced, white, untanned, pupal right prothoracic leg; eyes with characteristic adult pigmentation; partially tanned antennae, legs and wings; some patches of dorsal surface of thorax and anterior abdomen devoid of scales (Plate 1p) or intermediate with white, untanned proboscis and the right proboscis extremely reduced (Plate 1q)

Administration of seed and root extracts of W. somnifera to prepupae of $P$. ricini also resulted into formation of pupal-adult intermediates. These pupal-adult intermediates could be broadly classified into following types:

1. Pupal-adult intermediate consisting of white, untanned, bifurcated proboscis, labial palpi, wings and abdomen pupal in appearance except the posterior extremity of the abdomen whereas pigmented eyes, less tanned antennae, and thoracic legs exhibited adult characteristics; scales absent from dorsal surface of thorax; genitalia undeveloped (Plate 2x).

2. Pupal-adult intermediate with adult characteristics except white, bifurcated pupal proboscis (Plate 2y) or intermediate also showing white, untanned, reduced right metathoracic leg (Plate $2 \mathrm{z}$ ) or intermediate with reduced left wing (Plate 2aa) or intermediate with white, untanned right prothoracic leg; a few scales present on dorsal surface of thorax and anterior abdomen (Plate 2bb).

3. Pupal-adult intermediate with white, untanned, bifurcated proboscis; antennae and thoracic legs less tanned; wings with a few scales, whereas dorsal surface of thorax, anterior, and middle abdomen devoid of scales; genitalia undeveloped (Plate $2 \mathrm{cc}$ ).

\section{Adult emergence}

Administration of seed extracts to prepupae of S. litura and $P$. ricini resulted into suppression of adult emergence in a dose dependent manner. There was a negative correlation between the doses administered and percentage of adult emergence both in S. litura $(r=-$ 0.84) (Table 1) and P. ricini $(r=-0.85)$ (Table 3).

Adult emergence was also reduced by administration of root extracts of W. somnifera to prepupae of S. litura and $P$. ricini. There was a negative correlation between the doses applied and incidence of adult emergence both in case of S. litura $(r=0.74)$ (Table 2) and P. ricini $(r=-$ 0.75) (Table 4).

\section{Larval-pupal-adult intermediates}

Topical administration of seed and root extracts of $W$. somnifera to prepupae of $P$. ricini resulted into formation of larval-pupal-adult intermediates, whereas these were not produced in case of S. litura (Tables 3 and 4).

Depending upon the larval/pupal/adult characters, these could be broadly divided into the following types:

1. Larval-pupal-adult intermediate with white, bifurcated proboscis; partially tanned antennae and thoracic legs; left prothoracic leg and wing reduced; scars of larval prolegs present; eyes with characteristic adult pigmentation; some parts of abdomen both on the dorsal and ventral surface, and wings not fully darkened and showing white pupal integument (Plate 2ff).

2. Larval-pupal-adult intermediate with white, bifurcated pupal proboscis; rudimentary larval prolegs found and rest characters similar to those of adult (Plate 2gg).

\section{Adultoids}

Topical administration of seed and root extracts of $W$. somnifera to prepupae of $S$. litura resulted into formation of adultoids.

Depending upon degree of abnormalities, these have been classified into the following types-

1. Adultoids with coiled and bifurcated proboscis; crumpled wings; parts of middle and posterior abdomen on dorsal surface devoid of scales (Plate 1 $\mathrm{t}, \mathrm{u})$.

2. Adultoid with less scales on crumpled wings, dorsal thorax, and abdomen; proboscis bifurcated; right prothoracic leg reduced as compared to left prothoracic leg (Plate 1v, w).

3. Adultoid pupal exuviae not shed off, covering the head and thorax; abdomen covered with usual scales but genitalia not developed (Plate 1x).

4. Adultoid with pupal exuviae attached to ventral surface of head and thorax; a few scales present on the dorsal surface of anterior and middle abdomen (Plate 1y).

5. Adultoid with crumpled wings and deformed body unable to eclose from pupal exuviae (Plate 1z). In 
some cases, pupal exuviae remained attached to abdomen (Plate 1aa) or right wing (Plate 1bb). In some cases, adultoids unable to eclose from the pupal cuticle and the larval cuticle was also found attached to the posterior extremity of the body (Plate $1 \mathrm{cc}$ ).

Treatment of prepupae of $P$. ricini with seed and root extracts of $W$. somnifera also resulted into formation of adultoids. Adultoid with white, untanned, bifurcated proboscis, and right wing unable to eclose from pupal exuviae was produced (Plate $2 \mathrm{hh}$ ). In some cases, adultoid with coiled, bifurcated proboscis, and crumpled wings (Plate 2ii) or adultoid devoid of scales in the region of head and thorax and a few scars of scales found on the anterior and middle abdomen also developed (2jj). In some adultoids, the right wing (Plate $2 \mathrm{kk}$ ) or left wing were reduced (Plate 2ll).

\section{Discussion}

Topical administration of seed extracts of W. somnifera to prepupae of S. litura and P. ricini was more severe as it alone caused toxicity in a dose-dependent manner as compared to root extracts where no toxicity was observed. This is comparable with the similar findings in $P$. ricini where treatment with seed extracts produced toxic effects but not with the root extracts of W. somnifera (Gaur \& Kumar, 2017b). These toxicological effects may be due to the presence of certain bioactive compounds such as withanolide-WS-2 (aliphatic ester), withanolide-WS-1 (aliphatic ketone) in the seeds of $W$. somnifera (Dar et al., 2015). Such kind of toxic effect has also been observed as a result of treatment of developmental stages of other lepidopterans with extracts of $W$. somnifera, for instance, treatment of sixth instar larvae of S. litura with leaves extracts (Gaur \& Kumar, 2010) and root extracts (Gaur \& Kumar, 2017a).

The prepupal and pupal-adult ecdysis duration were significantly prolonged as a consequence of administration of seed and root extracts of W. somnifera to prepupae of both the lepidopterans viz. S. litura and P. ricini. The treatment with seed extracts has not only been found to be more effective in the prolongation of pupal-adult ecdysis in both the insects viz. S. litura and $P$. ricini but also resulting into the prolongation of prepupal period in S. litura, whereas the administration of root extracts only caused the prolongation of prepupal period in P. ricini. The crude volatile oil from the leaves of Piper betle has also been reported to cause prolongation of larval and pupal durations in the lepidopteran insect, S. litura (Srinivasan et al., 2016). In several cases, the plant extracts or their active bio ingredients have been observed to prolong larval and pupal duration when administered to different larval instars of lepidopteran insects. This has been observed as a result of administration of azadirachtin, salannin, deacetylgedunin, gedunin, 17-hydroxyazadiradion, and deacetylnimbin (limonoids) from Azadirachta indica to first to fifth instar larvae of Cnaphalocrocis medinalis (Lepidoptera: Crambidae) (Nathan, Kalaivani, Sehoon, \& Murugan, 2006); leaves, root, fruit extracts of Pedalium murex to fourth instar larvae of S. litura (Sahayaraj \& Sathyamoorthi, 2010); ononitol monohydrate isolated from leaves extracts of Cassia tora to third instar larvae of Helicoverpa armigera (Lepidoptera: Noctuidae), and $S$. litura (Baskar \& Ignacimuthu, 2012). Such type of prolongation of developmental period was similar to that produced by the administration of juvenile hormone analogue (JHA), pyriproxyfen, to different larval instars of lepidopteran insects viz. fifth instar larvae of Choristoneura rosaceana (Lepidoptera: Tortricidae) (Sial \& Brunner, 2010), second instar larvae of S. littoralis (Nasr, Badawy, \& Rabea, 2010), and third instar larvae of Plutella xylostella (Lepidoptera: Plutellidae) (Alizadeh et al., 2012). In addition to that, administration of botanical extracts/natural products causing prolongation of developmental stages in other insects have also been described such as seed extracts of $A$. indica and leaves extracts of Citrullus colocynthis in Schistocerca gregaria (Orthoptera: Acrididae) (Nassar, Ghazawy, Torkey, \& Rawy, 2018); rotenone from the roots of Lanochocrapus species or Derris species and limonine from citrus fruit peels in the vector of Bancroftian filariasis, Culex $(C x$.) pipiens pallens (Bakr, Nassar, El-Barky, Abdeldayem, \& Kotb, 2018). This kind of prolongation of prepupal and pupal duration is obviously due to inhibition/interference with the molting process, caused by an increase in the juvenile hormone $(\mathrm{JH})$ titer in the insect body (Hangartner \& Masner, 1973; Lapcharoen et al., 2005). There are two JH sensitive periods found in the last instar larvae of holometabolous insects. During these periods, the presence of $\mathrm{JH}$ is not required so that the cells of a developmental stage become committed to a new developmental fate (Nijhout, 1998). If the $\mathrm{JH}$ is present during these sensitive periods, the current developmental state or status quo will be maintained (Nijhout, 1998) and the switch to next developmental stage will not take place (Riddiford, Hiruma, Zhou, \& Nelson, 2003). This clearly demonstrates that the plant extracts from the medicinal plant, Ashwagandha, W. somnifera mimic the action of $\mathrm{JH}$ producing similar effects as with the exogenous administration of JHAs as the presence of JHAs during sensitive/critical period may lead to inhibition of ecdysone production or alteration of ecdysteroid titer in the insect body (Alizadeh et al., 2012; Ghasemi, Sendi, \& Ghadamyari, 2010; Suzuki, Sakurai, \& Iwami, 2010).

Another prominent and conspicuous effect of administration of seed and root extracts of W. somnifera to 
prepupae of S. litura and P. ricini is the inhibition of ecdysis/molting eventually leading to death of the treated insects. The insects suffering from ecdysial stasis were unable to cast off old larval cuticle that was found all over the body resulting into complete ecdysial stasis or remained attached to different parts of the pupal body showing partial ecdysial stasis. These effects have also been observed as a result of administration of IGRs (lufenuron and diflubenzuron) to fifth instar larvae of $H$. armigera (Butter, Singh, \& Dhawan, 2003; Unsal, Ozparlak, \& Aktumsek, 2004) and JHAs (diofenolan and pyriproxyfen) to last instar larvae of Papilio demoleus (Lepidoptera: Papilionidae) and S. litura (Singh \& Kumar, 2011a, 2011b, 2015a). In the last larval stadium of holometabolous insects, the $\mathrm{JH}$ titer is high during the initial phase of final stadium but subsequently it declines to undetectable levels. In the absence of $\mathrm{JH}$, the prothoracicotropic hormone (PTTH) is released from the neurosecretory cells and that induces the synthesis of ecdysteroids from prothoracic glands to initiate metamorphosis (Bollenbacher, Smith, Goodman, \& Gilbert, 1981; Gilbert, Iatrou, \& Gill, 2005; Rountree \& Bollenbacher, 1986). The ecdysial failure induced by $W$. somnifera extracts in both the insects viz. S. litura and P. ricini is similar to that induced by JHAs/IGRs and obviously due to hormonal imbalance as the exogenous administration of JHA, hydroprene, to rice weevil, Sitophilus oryzae (Coleoptera: Curculionidae) results into ecdysial failure because of the interference with the release of brain hormones (PTTH) (Gupta \& Mkhize, 1983). It has been suggested that the administration of phytochemicals like azadirachtin from $A$. indica and goniothalamin from leaves of Goniothalamus species caused molting inhibition due to interference with the endocrine system by disrupting the synthesis and release of ecdysteroids or due to modification and suppression of the ecdysteroids titer (Nathan, Choi, Paik, \& Kalaivani, 2008; Sieber \& Rembold, 1983). The phytochemicals such as azadirachtin and podophyllotoxin can interfere with the neuroendocrine system by blocking directly the release of morphogenetic peptides (PTTH) (Mordue (Luntz \& Nisbet, 2000; Garcia \& Azambuja, 2004). Therefore, plant extracts from $W$. somnifera are similar in action to IGRs as both act by interfering with the neuroendocrine control.

The formation of larval-pupal and pupal-adult intermediates as a consequence of treatment with seed and root extracts of $W$. somnifera to prepupae of S. litura and $P$. ricini is similar to those produced as a result of treatment of noctuid larvae with other plant extracts or their active bio ingredients such as leaves, root, fruit extracts of $P$. murex in S. litura (Sahayaraj \& Sathyamoorthi, 2010); seed extracts of Ceasalpinea bonduc in S. litura (Baskar, Maheswaran, \& Ignacimuthu, 2012); triterpenoid friedelin isolated from leaves of Azima tetracantha in H. armigera and S. litura (Baskar, Duraipandiyan, \& Ignacimuthu, 2014); and pogostone, an active ingredient of patchouli oil isolated from leaves of Pogostemon cablin in Spodoptera exigua (Huang et al., 2014). Surprisingly, administration of JHAs has also been observed to produce such intermediates in several lepidopteran insects, as observed in the present study or treatment with different IGRs. For instance, ethyl 11-chloro-3,7,11-trimethyldodec-2-trans-enoate application caused the development of larval-pupal and pupal-adult intermediates in Tortrix viridana (Lepidoptera: Tortricidae) (Novak \& Sehnal, 1973); methoprene caused formation of pupal-adult intermediates in S. littoralis (Kocak \& Kilincer, 1997); pyriproxyfen and diofenolan caused production of larval-pupal intermediates in S. litura (Singh \& Kumar, 2015a). The formation of intermediates/chimeras having larval, pupal, and adult characteristics as a result of administration of seed and root extracts of $W$. somnifera to $P$. ricini have also been observed with IGR (Gaur \& Kumar, 2017b) and JHAs like diofenolan and pyriproxyfen (Singh \& Kumar, 2011a, 2011b). It has been suggested that the phytochemicals/secondary metabolites of plants act as $\mathrm{JH}$ mimics (Bede \& Tobe, 2000) and are responsible for interference with the normal hormonal coordination of the metabolic processes of the developing stages (Sakthivadivel \& Thilagavathy, 2003). Moreover, it has been found that the administration of fruit extracts of Melia azedarach significantly increased $\mathrm{JH}$ titer in the hemolymph as compared to that of controls in treated larvae of S. littoralis and this high JH titer is responsible for insufficient development of pupal characters leading to the formation of larval-pupal intermediates (Schmidt, Rembold, Ahmed, \& Breuer, 1998). Infact, appropriate titres of $\mathrm{JH}$ and ecdysone during larval-pupal ecdysis in the insect determine the commitment of metamorphosis of larva into pupa (Doane, 1973; Nijhout, 1998). Infact, the presence or absence of $\mathrm{JH}$ during metamorphosis determines the course of development. The presence of $\mathrm{JH}$ during at an inappropriate time during the molting process prevents cellular differentiation and in the absence of $\mathrm{JH}$, morphogenesis and maturation occurs and the development proceeds towards the adult stage (Bowers, 1971). Therefore, any exogenous application of $\mathrm{JH} / \mathrm{JHAs} / \mathrm{IGRs}$ or plant extracts that mimic the $\mathrm{JH}$ action prevents the maturation and leads to the formation of nonviable intermediates. The larval-pupal intermediates thus formed remain as such or in a state of status quo when JH titer remains high (Metwally \& Sehnal, 1973).

Administration of seed and root extracts of W. somnifera also resulted into a significant reduction in pupation and adult emergence in both the insects viz. S. litura and P. ricini. The effect was observed in a dose-dependent 
manner in case of treatment with seed extracts of W. somnifera. These effects are similar to those observed by the treatment of larvae of Spodoptera spp. with various plant extracts such as Commiphora molmol (Family: Burseraceae), Pedalium murex (Family: Pedaliaceae), Condalia microphylla (Family: Rhamnaceae), and Calceolaria talcana (Family: Calceolariaceae) (Cespedes et al., 2013; Munoz, Lamilla, Marin, Alarcon, \& Cespedes, 2013; Sahayaraj \& Sathyamoorthi, 2010; Shonouda, Farrag, \& Salama, 2000). Moreover, it is interesting to note that such effects have also been observed as a result of treatment of lepidopteran larvae with JHAs, pyriproxyfen and diofenolan (Oouchi, 2005; Singh \& Kumar, 2015a). This clearly demonstrates that the plant extracts mimic the action of $\mathrm{JH}$ in this respect and pupation is inhibited/suppressed due to high $\mathrm{JH}$ titer (Eto, 1990; Kotaki, Nakakita, \& Kuwahara, 1993), whereas during the normal course of development $\mathrm{JH}$ is virtually absent in the pupae (Tunaz \& Uygun, 2004). Similarly, JHA, diofenolan, has also been reported to reduce pupation and completely blocking adult emergence and this inhibitory effect on adult emergence is possibly due to suppression/interference with the release of eclosion hormone (Ghoneim, Bream, Tanani, \& Nassar, 2007). Thus the effect produced by seed and root extracts of $W$. somnifera is comparable with a phytochemical, azadirachtin, which has been reported to block the synthesis/release of eclosion hormone (Rembold, Sharma, Czoppelt, \& Schmutterer, 1982).

The development of abnormal pupae and adultoids as a consequence of treatment of S. litura and P. ricini prepupae with seed and root extracts of $W$. somnifera have also been reported with other plant extracts/active bio ingredients (Cespedes, Salazar, Martinez, \& Aranda, 2005; Colom, Neske, Popich, \& Bardon, 2007; Martinez \& Emden, 2001; Paulraj, Shanmugam, \& Ignacimuthu, 2014; Sahayaraj \& Sathyamoorthi, 2010; Schmutterer, Saxena, \& Heyde, 1983; Sivaraman et al., 2017) or treatment with JHAs (pyriproxyfen, methoprene, fenoxycarb) (Alizadeh et al., 2012; El-Sheikh, Kamita, \& Hammock, 2016; Ghasemi et al., 2010). There is an additional $\mathrm{JH}$-sensitive period in the initial phase of pupal development for pupal versus adult determination (Nijhout, 1998) and if JH/JHA is present during this critical period, it disrupts the normal pupal development producing deformed adults or adultoids and interfering with adult eclosion (Alizadeh et al., 2012). This high level of endogenous $\mathrm{JH}$ exerts an inhibitory effect on proliferation of imaginal dics-derived cell line (Oberlander, Leach, \& Shaaya, 2000), which ultimately results in the disruption of pupal-adult development and inhibition of eclosion.

In present study, some of the adultoids were unable to eclose properly from pupal exuviae or pupal exuviae remained attached to different parts of the body. This kind of detrimental effect on adult eclosion has also been observed as a consequence of treatment with plant extracts or their active ingredients (Lapcharoen et al, 2005; Nenaah, 2011; Soonwera \& Phasomkusolsil, 2016; Sreelatha, Hymavathi, Rao, Devanand, \& Rani, 2010). The plant extracts mimic the action of JHAs as exogenous administration of JHAs exert inhibitory effect on the neuropeptide, eclosion hormone, produced by the ventral tritocerebral neurosecretory cell which leads to inhibition of adult eclosion (Singh \& Kumar, 2015a, 2015b).

\section{Conclusion}

Seed and root extracts from the medicinal herb, W. somnifera caused disruption of molting and metamorphosis and this may be due to interference with the neuroendocrine mechanism in the polyphagous pests, S. litura and $P$. ricini. These results show that extracts of W. somnifera mimic the action of $\mathrm{JH} / \mathrm{JHAs}$ and that can be judicially employed for the control of polyphagous insects under field conditions along with other bio-rational approaches of insect pest management.

\section{Acknowledgements \\ Authors are highly grateful to the Head, Department of Zoology, University of Allahabad, Prayagraj (India) for providing laboratory assistance. \\ Funding \\ Not applicable. \\ Availability of data and materials \\ Please contact author for data requests. \\ Authors' contributions \\ All the authors contributed equally for experimental design, observation, manuscript preparation, and correction. Both the authors read and approved the final manuscript.}

Ethics approval and consent to participate

Not applicable.

Consent for publication

Not applicable.

\section{Competing interests}

The authors declare that they have no competing interests.

\section{Publisher's Note}

Springer Nature remains neutral with regard to jurisdictional claims in published maps and institutional affiliations.

Received: 12 December 2018 Accepted: 1 May 2019

Published online: 22 May 2019

References

Abbas, N., Shad, S. A., \& Razaq, M. (2012). Fitness cost, cross resistance and realized heritability of resistance to imidacloprid in Spodoptera litura (Lepidoptera: Noctuidae). Pesticide Biochemistry and Physiology, 103(3), 181188

Ahmad, M., Arif, M. I., \& Ahmad, M. (2007). Occurrence of insecticide resistance in field populations of Spodoptera litura (Lepidoptera: Noctuidae) in Pakistan. Crop Protection, 26, 809-817. 
Ahmad, M., Ghaffar, A., \& Rafiq, M. (2013). Host plants of leaf worm, Spodoptera litura (Fabricius) (Lepidoptera: Noctuidae) in Pakistan. Asian J Agri Biol, 1(1), 23-28.

Ahmad, M., Sayyed, A. H., Saleem, M. A., \& Ahmad, M. (2008). Evidence for field evolved resistance to newer insecticides in Spodoptera litura (Lepidoptera: Noctuidae) from Pakistan. Crop Protection, 27, 1367-1372.

Alam, N., Hossain, M., Khalil, M. I., Moniruzzaman, M., Sulaiman, S. A., \& Gan, S. H. (2012). Recent advances in elucidating the biological properties of Withania somnifera and its potential role in health benefits. Phytochemistry Reviews, 11, 97-112.

Alizadeh, M., Karimzadeh, J., Rassoulian, G. R., Farazmand, H., Hoseini-Navah, V., \& Pourian, H. R. (2012). Sublethal effects of pyriproxyfen, a juvenile hormone analogue, on Plutella xylostella (Lepidoptera: Plutellidae): Life table study. Archives of Phytopathology and Plant Protection, 45(14), 1741-1763.

Badawy, M. I. (1998). Use and impact of pesticides in Egypt. International Journal of Environmental Health Research, 8(3), 223-239.

Bakr, R. F. A., Nassar, M. I., El-Barky, N. M., Abdeldayem, M. S., \& Kotb, T. F. (2018). Effect of some natural products on the vector of Bancroftian filariasis in Jizan KSA. Egyptian Academic Journal of Biological Sciences, 10(1), 1-11.

Baskar, K., Duraipandiyan, V., \& Ignacimuthu, S. (2014). Bioefficacy of the triterpenoid friedelin against Helicoverpa armigera (Hub.) and Spodoptera litura (Fab.) (Lepidoptera: Noctuidae). Pest Management Science, 70, 1877-1883.

Baskar, K., \& Ignacimuthu, S. (2012). Antifeedant, larvicidal and growth inhibitory effects of ononitol monohydrate isolated from Cassia tora L. against Helicoverpa armigera (Hub.) and Spodoptera litura (Fab.) (Lepidoptera: Noctuidae). Chemosphere, 88, 384-388.

Baskar, K., Maheswaran, R., \& Ignacimuthu, S. (2012). Bioefficacy of Ceasalpinea bonduc (L.) Roxb. Against Sopdoptera litura Fab. (Lepidoptera: Noctuidae). Archives of Phytopathology and Plant Protection, 45(10), 1127-1137.

Bede, J. C., \& Tobe, S. S. (2000). Insect juvenile hormones in plants. Studies in Natural Products Chemistry, 22part C, 369-418

Bhattacharya, S. K., Bhattacharya, A., Sairam, K., \& Ghosal, S. (2000). Anxiolyticantidepressant activity of Withania somnifera glycowithanolides: an experimental study. Phytomedicine, 7(6), 463-469.

Bollenbacher, W. E., Smith, S. L., Goodman, W. G., \& Gilbert, L. I. (1981). Ecdysteriod titre during larval-pupal-adult development of the tobacco hornworm, Manduca sexta. General and Comparative Endocrinology, 44, 302-306.

Bowers, W. S. (1971). Insect hormones and their derivatives as insecticides. Bull Org mond Sante Bull WId Hlth Org, 44, 381-389.

Brittain, C. A., Vighi, M., Bommarco, R., Settele, J., \& Potts, S. G. (2010). Impacts of a pesticide on pollinator species richness at different spatial scales. Basic and Applied Ecology, 11, 106-115.

Butter, N. S., Singh, G., \& Dhawan, A. K. (2003). Laboratory evaluation of the insect growth regulator lufenuron against Helicoverpa armigera on cotton. Phytoparasitica, 31(2), 200-203.

Cespedes, C. L., Molina, S. C., Munoz, E., Lamilla, C., Alarcon, J., Palacios, S. M., ... Avila, J. G. (2013). The insecticidal, molting disruption and insect growth inhibitory activity of extracts from Condalia microphylla Cav. (Rhamnaceae). Industrial Crops and Products, 42, 78-86.

Cespedes, C. L., Salazar, J. R., Martinez, M., \& Aranda, E. (2005). Insect growth regulatory effects of some extracts and sterols from Myrtillocacctus geometrizans (Cactaceae) against Spodoptera frugiperda and Tenebrio molitor. Phytochemistry, 66, 2481-2493.

Chaturvedi, M., Sharma, C., \& Chaturvedi, M. (2013). Effects of pesticides on human beings and farm animals: a case study. Research Journal of Chemical and Environmental Sciences, 1(3), 14-19.

Colom, O. A., Neske, A., Popich, S., \& Bardon, A. (2007). Toxic effects of annonaceous acetogenins from Annona cherimolia (Magnoliales: Annonaceae) on Spodoptera frugiperda (Lepidoptera: Noctuidae). Journal of Pest Science, 80, 63-67.

Damalas, C. A., \& Eleftherohorinos, I. G. (2011). Pesticide exposure, safety issues and risk assessment indicators. International Journal of Environmental Research and Public Health, 8, 1402-1419.

Dar, N. J., Hamid, A., \& Ahmad, M. (2015). Pharmacologic overview of Withania somnifera, the Indian ginseng. Cellular and Molecular Life Sciences, 72, 44454460.

David, B. V., \& Ananthakrishnan, T. N. (2004). General and applied entomology. New Delhi: Tata McGraw-Hill Publishing Company limited.

Dhir, B. C., Mohapatra, H. K., \& Senapati, B. (1992). Assessment of crop loss in groundnut due to tobacco caterpillar, Spodoptera litura (F.). Indian Journal of Plant Protection, 20(2), 215-217.
Divya, D. (2016). Management of Spodoptera litura. Imperial Journal of Interdisciplinary Research, 2(5), 285-289.

Doane, W. W. (1973). In J. S. Counce, \& C. H. Waddington (Eds.), In developmental system: Insects. Vol 2, (p. 291). London and New York: Academic

El-Sheikh, E. S. A., Kamita, S. G., \& Hammock, B. D. (2016). Effects of juvenile hormone $(\mathrm{JH})$ analog insecticides on larval development and $\mathrm{JH}$ esterase activity in two spodopterans. Pesticide Biochemistry and Physiology, 128, 30-36.

El-Wakeil, N. E. (2013). Botanical pesticides and their mode of action. Gesunde Pflanzen, 65(4), 125-149.

Eto, M. (1990). Biochemical mechanism of insecticidal activities. In G. Haug, \& Hoffman (Eds.), Chemistry of plant protection, (vol. Vol. 6, pp. 65-107). Berlin: Springer -Verlag.

Garcia, E. S., \& Azambuja, P. (2004). Lignoids in insects: chemical probes for the study of ecdysis, excretion and Trypanosoma cruzi - Triatomine interactions. Toxicon, 44, 431-440.

Gaur, R., \& Kumar, K. (2010). Insect growth-regulating effects of Withania somnifera in a polyphagous pest, Spodoptera litura. Phytoparasitica, 38, 237-241.

Gaur, S. K., \& Kumar, K. (2017a). Bioefficacy of root extracts of a medicinal plant, Withania somnifera (Dunal) against a polyphagous pest, Spodoptera litura (Fabricius) (Lepidoptera: Noctuidae). Archives of Phytopathology and Plant Protection, 50(15-16), 802-814.

Gaur, S. K., \& Kumar, K. (2017b). Withania somnifera acts as a potential insect growth regulator in the polyphagous pest, Pericallia ricini. Journal of Plant Protection Research, 57(4), 379-388.

Ghasemi, A., Sendi, J. J., \& Ghadamyari, M. (2010). Physiological and biochemical effect of pyriproxyfen on Indian meal moth Plodia interpunctella (Hubner) (Lepidoptera: Pyralidae). Journal of Plant Protection Research, 50(4), 416-422.

Ghoneim, K. S., Bream, A. S., Tanani, M. A., \& Nassar, M. I. (2007). Efficacy of lufenuron (CGA-184699) and diofenolan (CGA-59205) on survival, growth and development of the red palm weevil, Rhynchophorous ferrugineus (Coleoptera: Curculionidae), (pp. 246-279). Ghent: 59th Int. Symposium on Crop Protection.

Gilbert, L. I., latrou, K., \& Gill, S. S. (2005). Comprehensive molecular insect science (1st ed), (vol. 3, pp. 1-896). Oxford: Elsevier Ltd.

Gill, H. K., \& Garg, H. (2014). In S. Soloneski (Ed.), Tech Pesticides: environmental impacts and management strategies, pesticides - toxic aspects, (p. 238).

Gupta, A. P., \& Mkhize, J. M. (1983). Developmental and morphogenetic effects of two insect growth regulators (hydroprene and R-20458) on the female rice weevil, Sitophilus Oryzae (L.) (Coleoptera: Curculionidae). Appl Ent Zool, 18(1), 11-21.

Hangartner, W., \& Masner, P. (1973). Juvenile hormone: inhibition of ecdysis in larvae of the German cockroach Blatella germania. Experientia, 29, 1358-1359.

Huang, S. H., Xian, J. D., Kong, S. Z., Li, Y. C., Xie, J. H., Lin, J., ... Su, Z. R. (2014). Insecticidal activity of pogostone against Spodoptera litura and Spodoptera exigua (Lepidoptera: Noctuidae). Pest Management Science, 70, 510-516.

Ibrahim, Y. A. (2016). Health and environmental impacts of pesticides: a responsibility principle and two novel systems for hazard classification and external cost determination. Journal of Toxicology and Health, 3(1). https://doi. org/10.7243/2056-3779-3-1.

Isman, M. B. (2006). Botanical insecticides, deterrents, and repellents in modern agriculture and an increasingly regulated world. Annual Review of Entomology, 51, 45-66.

Khan, M., \& Damalas, C. A. (2015). Occupational exposure to pesticides and resultant health problems among cotton farmers of Punjab, Pakistan. International Journal of Environmental Health Research, 25(5), 508-521.

Kocak, E., \& Kilincer, N. (1997). Investigations on the effects of juvenile hormone analogue methoprene to of cotton leafworm [Spodoptera littoralis (Boisd. )(Lep.: Noctuidae)]: I. effects on pupae and eggs. Bitik Koruma bulteni, 37(3-4), 163-172.

Kotaki, T., Nakakita, H., \& Kuwahara, M. (1993). Crowding inhibits pupation in Tribolium freeman (Coleoptera: Tenebrionidae): effects of isolation and juvenile hormone analogues on development and pupation. Applied Entomology and Zoology, 28(1), 43-52.

Kranthi, K. R., Jadhav, D. R., Kranthi, S., Wanjari, R. R., Ali, S. S., \& Russell, D. A. (2002). Insecticide resistance in five major insect pests of cotton in India. Crop Protection, 21, 449-460.

Lapcharoen, P., Apiwathnasorn, C., Komalamisra, N., Dekumyoy, P., Palakul, K., \& Rongsriyam, Y. (2005). Three indigenous Thai medicinal plants for control of Aedes aegypti and Culex quinquefasciatus. The Southeast Asian Journal of Tropical Medicine and Public Health, 36(suppl 4), 167-175.

Maksymiv, I. (2015). Pesticides: benefits and hazards. Journal of Vasyl stefanyk Precarpathian National University, 2(1), 70-76. http://journals.pu.if.ua/index. php/jpnu/article/view/507/553. 
Martinez, S. S., \& Emden, H. F. V. (2001). Growth disruption, abnormalities and mortality of Spodoptera littoralis (Boisduval) (Lepidoptera: Noctuidae) caused by azadirachtin. Neotropical Entomology, 30(1), 113-125.

Metwally, M. M., \& Sehnal, F. (1973). Effects of juvenile hormone analogues on the metamorphosis of beetles Trogoderma granarium (Dermestidae) and Caryedon gonagra (Bruchidae). The Biological Bulletin, 144, 368-382.

Mingo, V., Lotters, S., \& Wagner, N. (2016). Risk of pesticide exposure for reptile species in the European Union. Environmental Pollution, 215, 164-169.

Mokarizadeh, A., Faryabi, M. R., Rezvanfar, M. A., \& Abdollahi, M. (2015). A comprehensive review of pesticides and the immune dysregulation: mechanisms, evidence and consequences. Toxicology Mechanisms and Methods, 25, 258-278.

Mordue (Luntz, A. J., \& Nisbet, A. J. (2000). Azadirachtin from the neem tree Azadirachta indica: its action against insects. An Soc Entomol Brasil, 29(4), 615-632.

Munoz, E., Lamilla, C., Marin, J. C., Alarcon, J., \& Cespedes, C. L. (2013). Antifeedant, insect growth regulatory and insecticidal effects of Calceolaria talcana (Calceolariaceae) on the Drosophila melanogaster and Spodoptera frugiperda. Industrial Crops and Products, 42, 137-144.

Nasr, H. M., Badawy, M. E. I., \& Rabea, E. I. (2010). Toxicity and biochemical study of two insect regulators, buprofezin and pyriproxyfen, on cotton leafworm Spodoptera littoralis. Pesticide Biochemistry and Physiology, 98, 198-205.

Nassar, M. I., Ghazawy, N. A., Torkey, H. M., \& Rawy, S. M. (2018). Assessment of biorational botanical extracts on the desert locust Schistocerca gregaria Forskal (Orthoptera: Acrididae). Entomol App/ Sci Lett, 5(2), 42-54.

Nathan, S. S., Choi, M. Y., Paik, C. H., \& Kalaivani, K. (2008). The toxicity and physiological effect of goniothalamin, a styryl-pyrone, on the generalist herbivore, Spodoptera exigua Hubner. Chemosphere, 72, 1393-1400.

Nathan, S. S., Kalaivani, K., Sehoon, K., \& Murugan, K. (2006). The toxicity and behavioural effects of neem limonoids on Cnaphalocrocis medinalis (Guenee), the rice leaffolder. Chemosphere, 62, 1381-1387.

Nenaah, G. (2011). Toxicity and growth inhibitory activities of methanol extract and the $B$-carboline alkaloids of Peganum harmala $L$. against two coleopteran stored-grain pests. Journal of Stored Products Research, 47, 255-261.

Nijhout, H. F. (1998). Insect hormone, (4th ed., pp. 1-267). Princeton: Princeton University press.

Novak, V., \& Sehnal, F. (1973). Effects of a juvenoid applied under field conditions to the green oak leaf roller, Tortrix viridana L. (Lep., Tortricidae). Journal of Applied Entomology, 73(1-4), 312-318.

Oberlander, H., Leach, C. E., \& Shaaya, E. (2000). Juvenile hormone and juvenile hormone mimics inhibit proliferation in a lepidopteran imaginal disc cell line. Journal of Insect Physiology, 46, 259-265.

Oouchi, H. (2005). Insecticidal properties of a juvenoid, pyriproxyfen, on all life stages of the diamondback moth, Plutella xylostella (Lepidoptera: Yponomeutidae). Applied Entomology and Zoology, 40(1), 145-149.

Pant, M., Dubey, S., \& Patanjali, P. K. (2016). Recent advancements in biobotanical pesticide formulation technology development. In Herbal insecticides, repellents and biomedicines: effectiveness and commercialization, (pp. 117-126).

Paulraj, M. G., Shanmugam, N., \& Ignacimuthu, S. (2014). Antifeedant activity and toxicity of two alkaloids from Adhatoda vasica Nees leaves against diamondback moth Plutella xylostella (Linn.) (Lepidoptera: Plutellidae) larvae. Archives of Phytopathology and Plant Protection, 47(15), 1832-1840.

Rajapakse, R. H. S., Ratnasekera, D., \& Abeysinghe, S. (2016). Biopesticides research: current status and future trends in Sri Lanka. In Agriculturally important microorganisms, (pp. 219-234).

Rembold, H., Sharma, G. K., Czoppelt, C., \& Schmutterer, H. (1982). Azadirachtin: a potent insect growth regulator of plant origin. Zeitschrift für Angewandte Entomologie, 93, 12-17.

Riddiford, L. M., Hiruma, K., Zhou, X., \& Nelson, C. A. (2003). Insights into the molecular basis of the hormonal control of molting and metamorphosis from Manduca sexta and Drosophila melanogaster. Insect Biochemistry and Molecular Biology, 33, 1327-1338.

Rountree, D. B., \& Bollenbacher, W. E. (1986). The release of the prothoracicotropic hormone in the tobacco hornworm, Manduca sexta, is controlled intrinsically by juvenile hormone. The Journal of Experimental Biology, 120, 41-58.

Sahayaraj, K., \& Sathyamoorthi, P. (2010). The toxicity and biological effect of Pedalium murex L. extracts on the tobacco cutworm, Spodoptera litura (Fabr.) larvae. Archives of Phytopathology and Plant Protection, 43(18), 1768-1780.
Sakthivadivel, M., \& Thilagavathy, D. (2003). Larvicidal and chemosterilant activity of the acetone fraction of petroleum ether extract from Argemone mexicana L. seed. Bioresource Technology, 89, 213-216.

Schmidt, G. H., Rembold, H., Ahmed, A. A. I., \& Breuer, M. (1998). Effect of Melia azedarach fruit extract on juvenile hormone titre and protein content in the hemolymph of two species of noctuid lepidopteran larvae (Insecta: Lepidoptera: Noctuidae). Phytoparasitica, 26(4), 283-291.

Schmutterer, H., Saxena, R. C., \& Heyde, J. V. D. (1983). Morphogentic effects of some partially-purified fractions and methanolic extracts of neem seeds on Mythimna separate (Walker) and Cnaphalocrocis medinalis (Guenee). Z Ang Ent, 95, 230-237.

Shonouda, M. L., Farrag, R. M., \& Salama, O. M. (2000). Efficacy of the botanical extract (myrrh), chemical insecticides and their combinations on the cotton leafworm, Spodoptera littoralis Boisd (Lepidoptera: Noctuidae). Journal of Environmental Science and Health, B35(3), 347-356.

Sial, A. A., \& Brunner, J. F. (2010). Lethal and sublethal effects of an insect growth regulator, pyriproxyfen, on obliquebanded leafroller (Lepidoptera: Tortricidae). Journal of Economic Entomology, 103(2), 340-347.

Sieber, K. P., \& Rembold, H. (1983). The effects of azadirachtin on the endocrine control of moulting in Locusta migratoria. Journal of Insect Physiology, 29(6), 523-527.

Singh, A., \& Gandhi, S. (2012). Agricultural insect pest: occurrence and infestation level in agricultural fields of Vadodara, Gujarat. International Journal of Scientific and Research Publications, 2(4), 1-5.

Singh, S., \& Kumar, K. (2011a). Diofenolan: a novel insect growth regulator in common citrus butterfly, Papilio demoleus. Phytoparasitica, 39, 205-2013.

Singh, S., \& Kumar, K. (2011b). Effect of the juvenile hormone agonist pyriproxyfen on larval and pupal development of the citrus swallowtail Papilio demoleus (Lepidoptera: Papilionidae). International Journal of Tropical Insect Science, 31(3), 192-198.

Singh, S., \& Kumar, K. (2015a). Comparative efficacy of phenoxy derivative JHAs pyriproxyfen and diofenolan against polyphagous pest Spodoptera litura (Fabricius) (Noctuidae: Lepidoptera). Phytoparasitica, 43, 553-563.

Singh, S., \& Kumar, K. (2015b). Effects of jevenoid pyriproxyfen on reproduction and $\mathrm{F} 1$ progeny in myiasis causing flesh fly Sarcophaga ruficornis $\mathrm{L}$. Parasitology Research, 114(6), 2325-2331.

Sivaraman, G., Paulraj, M. G., Balakrishna, K., Irudayaraj, S. S., Ignacimuthu, S., \& AlDhabi, N. A. (2017). Biological effects of active fraction isolated from Hydnocarpus pentandra (Bunch. -Ham.) Oken seeds against Helicoverpa armigera (Hub.) (Lepidoptera: Nctuidae). Archives of Phyopathology and Plant protection, 50(5-6), 262-274.

Soonwera, M., \& Phasomkusolsil, S. (2016). Effect of Cymbopogon citratus (lemongrass) and Syzygium aromaticum (clove) oils on the morphology and mortality of Aedes aegypti and Anopheles dirus larvae. Parasitology Research, $115,1691-1703$.

Sreelatha, T., Hymavathi, A., Rao, R. S., Devanand, P., \& Rani, P. U. (2010). A new benzyl derivative from Derris scandens: structure-insecticidal activity study. Bioorganic \& Medicinal Chemistry Letters, 20, 549-553.

Srinivasan, P. V., Nathan, S. S., Thanigaivel, A., Edwin, E. S., Ponsankar, A., Rani, S. S., ... Al-Dhabi, N. A. (2016). Developmental response of Spodoptera litura Fab. To treatments of crude volatile oil from Piper betle $\mathrm{L}$. and evaluation of toxicity to earthworm, Eudrilus eugeniae Kinb. Chemosphere, 155, 336-347.

Suzuki, T., Sakurai, S., \& Iwami, M. (2010). Juvenile hormone delays the initiation of rectal sac distention by disrupting ecdysteroid action in the silkworm, Bombyx mori. Pesticide Biochemistry and Physiology, 97, 199-203.

Tong, H., Su, Q., Zhou, X., \& Bai, L. (2013). Field resistance of Spodoptera litura (Lepidoptera: Noctuidae) to organophosphate, pyrethroids, carbamates and four newer chemistry insecticides in Hunan, China. Journal of Pest Science, 86, 599-609.

Tunaz, H., \& Uygun, N. (2004). Insect growth regulators for insect pest control. Turkish Journal of Agriculture and Forestry, 28, 377-387.

Unsal, S., Ozparlak, H., \& Aktumsek, A. (2004). Effects of diflubenzuron on the integument of fifth instar Galleria mellonella larvae. Phytoparasitica, 32(1), 43-51.

Vanitha, K., Karuppuchamy, P., \& Sivasubramanian, P. (2011). Pests of vanilla (Vanilla planifolia Andrews) and their natural enemies in Tamil Nadu, India. International Journal of Biodiversity and Conservation, 3(4), 116-120.

Wan, M. T. (2013). Ecological risk of pesticide residues in the British Columbia environment: 1973-2012. Journal of Environmental Science and Health, B, 48, 344-363.

Witt, T. J., Muller, G. C., Kravchenko, V. D., Miller, M. A., Hausmann, A., \& Speidel, W. (2005). A new Olepa species from Israel. Nachrbl. Bayer. Ent., 54(3/4), 101-115.

Zacharia, J. T. (2011). In M. Stoytcheva (Ed.), in tech Ecological effects of pesticides, pesticides in the modern world —risks and benefits, (p. 560). 